\title{
Rosacea and the Microbiome: A Systematic Review
}

\author{
Hala Daou · Michela Paradiso · Kerry Hennessy · Lucia Seminario-Vidal
}

Received: September 23, 2020 / Published online: November 10, 2020

(c) The Author(s) 2020

\section{ABSTRACT}

Rosacea, a chronic inflammatory skin disease characterized by recurrent episodes of facial flushing, erythema, pustules, and telangiectasia, largely affects fair-skinned women over 30 years of age. Although a long-recognized entity, the exact pathophysiology of this disease is still debated. Current theories highlight the role of the cutaneous microbiome and its associated inflammatory effects in rosacea's pathogenesis. However, microbiological reverberations are not limited to the skin, as recent studies have described the potential cutaneous effects of alterations in the gastrointestinal (GI) microbiome. Associations with additional GI pathologies, including small intestinal bacterial

H. Daou

Morsani College of Medicine, University of South

Florida, Tampa, FL, USA

M. Paradiso

Ohio State University College of Medicine,

Columbus, $\mathrm{OH}$, USA

K. Hennessy · L. Seminario-Vidal ( $₫)$

Department of Dermatology and Cutaneous

Surgery, University of South Florida, Tampa, FL, USA

e-mail: luciasem@usf.edu overgrowth (SIBO), irritable bowel syndrome (IBS), and inflammatory bowel disease (IBD), have been investigated, as well as Helicobacter pylori infection. In an attempt to better understand and characterize these relationships, as well as current treatment options, we conducted a systematic review of the literature in PubMed, Cochrane, and Embase from their inception to August 6, 2020. We have synthesized the literature findings within three sections of this manuscript: the cutaneous microbiome, the gut microbiome, and therapeutic strategies. Future studies should focus on specific mechanisms linking GI pathology with rosacea manifestations and the role of enteral drugs in mitigating cutaneous symptoms.

Keywords: Rosacea; IBD; Microbiome; Inflammation; Immune dysregulation 


\section{Key Summary Points}

Rosacea is a chronic inflammatory skin disease characterized by recurrent episodes of facial flushing, erythema, pustules, and telangiectasia, largely affecting fair-skinned women over 30 years of age

Imbalances in cutaneous organisms including Cutibacterium acnes, Staphylococcus epidermidis, Bacillus oleronius, and Demodex folliculorum have been implicated in the pathogenesis of rosacea

An association between rosacea and numerous inflammatory gastrointestinal disorders has been reported in the literature

Treatments targeting the dysregulation of both the cutaneous and gastrointestinal microbiomes have proven efficacious

Future therapies should target gastrointestinal inflammation and dysbiosis as a means to ameliorate global immune system dysregulation and the ensuing symptoms of rosacea that arise

\section{DIGITAL FEATURES}

This article is published with digital features to facilitate understanding of the article. You can access the digital features on the article's associated Figshare page. To view digital features for this article go to https://doi.org/10.6084/m9. figshare.13089377.

\section{INTRODUCTION}

Rosacea is a chronic inflammatory skin disease characterized by recurrent episodes of facial flushing, erythema, papules, pustules, and telangiectasias on the central face with possible ocular and phymatous involvement [1]. It is divided into four principal subtypes based on these clinical characteristics: erythematotelangiectatic rosacea (ETR), papulopustular rosacea (PPR), phymatous rosacea, and ocular rosacea [2]. It affects between $0.9 \%$ and $10 \%$ of the population. Onset usually occurs after 30 years of age [1], and there is increased prevalence in women and fair-skinned individuals of European descent [2, 3]. In addition to these genetic elements, other well-established risk factors include increased alcohol consumption and excessive UV exposure $[4,5]$.

Although the exact pathophysiology of rosacea is debated, present theories implicate dysregulation of innate and adaptive immunity, aberrant neurovascular signaling, chronic inflammation, and the overgrowth of commensal skin organisms [6-8]. Importantly, the generation of reactive oxygen species (ROS) due to an altered innate immune response appears to be a component of rosacea's mechanism of disease, as studies have demonstrated higher levels of ROS in patients with this condition [3].

Interestingly, numerous associations between rosacea and inflammatory gastrointestinal (GI) tract disorders have been reported [9], and the effects of both skin and gut microbiota on rosacea's clinical course have been well studied. To better understand these associations, we conducted a review of the literature.

\section{METHODS}

\section{Eligibility Criteria and Evidence Search}

This article is based on previously conducted studies and does not contain any studies with human participants or animals performed by any of the authors. A systematic review on the associations between rosacea, the skin and gut microbiomes, and GI disorders was conducted. PubMed, Cochrane Central Register for Controlled Trials, and Embase databases were searched from their inception to August 6, 2020. The bibliographies of relevant reviews were also searched for potentially eligible studies. Included studies were limited to those published in English, but no other restrictions were imposed. 
The Medline search strategy was as follows: ((rosacea[MeSH Terms]) OR (rosacea[Title/Abstract])) AND (microbio*[Title/Abstract] OR microorg*[Title/Abstract] OR bacteria [Title/Abstract] OR fungus [Title/Abstract] OR virus [Title/Abstract] OR gastr*[Title/Abstract] OR GI[Title/Abstract]). This search gleaned 268 results. The Embase search strategy was as follows: (rosacea:ab,ti) AND (microorg*:ab,ti OR microbio*:ab,ti OR bacteria:ab,ti OR fungus:ab,ti OR virus:ab,ti OR gastr*:ab,ti OR gi:ab,ti). This search gleaned 407 results. The Cochrane search strategy was as follows: ((MeSH descriptor [Rosacea]) OR (Rosacea):ti,ab,kw)) AND ((microbio):ti,ab,kw OR (microorg):ti,ab,kw OR (bacteria):ti,ab,kw OR (fungus):ti,ab,kw OR (virus):ti,ab,kw OR (gastri $\left.^{*}\right): t i, a b, k w \quad$ OR (GI):ti,ab,kw) This search gleaned 33 results.

\section{Selection of Studies}

All study designs were eligible for inclusion. Out of the 708 papers gathered from searching the databases, 230 duplicates were removed. Then, 478 studies were divided for independent title and abstract screening between two of the authors (HD, KH). A total of 324 papers were deemed irrelevant after title and abstract screening, and 154 underwent full text review. The full text of potential studies was obtained and examined for eligibility by all authors. In this stage of data extraction, only those papers deemed most relevant to the topic of rosacea, the microbiome, and GI comorbidities were analyzed in depth, resulting in the inclusion of 36 publications, and 16 publications were added from reference text review.

\section{Data Extraction}

As this review is descriptive, numeric data was not extracted for statistical analysis. Qualitative information regarding the associations of interest was extracted from the included publications.

\section{DISCUSSION}

\section{The Cutaneous Microbiome}

Within the skin, as with most organ systems, the microbiome is essential in the facilitation of proper immune function. Several microorganisms including Demodex folliculorum, Bacillus oleronius, Staphylococcus epidermidis, and Cutibacterium acnes have been studied as potential players in rosacea's pathogenesis $[4,10]$. These microorganisms' abnormal activation of the innate immune system via Tolllike receptor 2 has been extensively investigated [7]. Moreover, when compared to normal skin, skin affected by rosacea has significantly more expression of cathelicidin, an antimicrobial peptide (AMP) expressed by both leukocytes and epithelial cells [2]. This can result in aberrant downstream effects, including leukocyte chemotaxis, vasodilation, angiogenesis, and extracellular matrix deposition [2]. And, these effects may ultimately contribute to the development of a dysbiotic cutaneous state. Cathelicidin may also represent a link between rosacea and irritable bowel disease (IBD), as significant elevations of this peptide were noted in the colonic mucosa of patients with IBD [11].

Despite these immunologic features, it is unclear whether microorganisms are causative agents or innocent bystanders in rosacea $[4,7]$. In other words, does dysbiosis precipitate rosacea, or does the altered cutaneous microenvironment precipitate dysbiosis?

\section{Demodex folliculorum}

Patients with rosacea demonstrate increased densities of Demodex mites (both Demodex brevis and D. folliculorum) in their skin compared with controls $[4,8]$. These mites inhabit the pilosebaceous unit wherein their food source is sebum or protein [8]. In a study aimed at quantifying Demodex, Casas et al. found D. folliculorum levels in patients with rosacea to be 5.7 times greater than controls [12]. Additionally, an association was noted between $D$. folliculorum and inflammatory markers, suggesting a deleterious activation of the innate immune system [12]. The 
cytokines observed (including interleukin-8 (IL8 ) and tumor necrosis factor alpha (TNF $\alpha)$ ) promote angiogenesis, highlighting a potential cause of the long-standing, prominent telangiectasias often present in rosacea. It has been suggested that D. folliculorum's exoskeleton itself incites the production of inflammatory markers [13].

\section{Bacillus oleronius}

In an additional layer of complexity, B. oleronius, a gram-negative Demodex-associated bacteria, triggers inflammatory pathways in its own right $[7,8,13]$. This microorganism has been demonstrated to produce antigenic proteins that potentially play a role in PPR, ETR, and ocular rosacea [8]. According to O'Reilly et al., $80 \%$ of patients with ETR displayed serum reactivity to the $62-$ and $83-\mathrm{kDa}$ proteins produced by B. oleronius compared to $40 \%$ of controls [8]. And, in a follow-up study, they found that neutrophils exposed to proteins from B. oleronius cells demonstrated increased chemotaxis, elevated release of matrix metalloproteinase-9, and increased levels of the pro-inflammatory cytokines IL-8 and $\mathrm{TNF} \alpha$ [14].

The efficacy of antibiotics such as tetracyclines in the reduction of inflammation associated with rosacea further corroborates the theory of a bacterial etiology, being that tetracyclines are ineffective in the eradication of Demodex mites. Nonetheless, opinions differ as to whether the beneficial effects of tetracyclines are derived from their antimicrobial or inherent anti-inflammatory properties.

\section{Staphylococcus epidermidis}

In a study by Holmes, the commensal bacterium S.epidermidis was detected in copious amounts in the pustular lesions of patients with rosacea [4]. Similarly, Whitfeld et al. compared skin affected by rosacea with adjacent unaffected skin, finding a significant increase in pure growth of $S$. epidermidis from rosacea pustules in comparison with normal skin [15]. This microbe's posited pathogenic role highlights the cyclical nature of the condition's etiology. In rosacea, increased cutaneous blood flow to the face leads to an elevated temperature that is, at times, clinically detectable [15]. S. epidermidis, among a variety of other bacteria, behaves differently at higher temperatures, producing divergent proteins that may act as virulence factors not otherwise found in healthy controls $[4,15]$. Therefore, in this context, the altered microenvironment of rosacea-affected skin could potentiate exacerbation of symptoms due to a shift in microflora [4].

\section{Cutibacterium acnes}

It is important to note that a decrease in the abundance of certain microorganisms could also play a role in rosacea's pathogenesis. Sebaceous areas such as the back, face, and postauricular region tend to be colonized by high proportions of the lipophilic bacteria C.acnes (formerly Propionibacterium acnes). C.acnes hydrolyzes triglycerides found in sebum, thus releasing free fatty acids that function to acidify and emolliate the skin. Wang et al. found that C. acnes was dominant on healthy facial skin, and its relative abundance was significantly decreased in both the ETR and PPR subtypes of rosacea [10].

\section{The Gut Microbiome}

\section{The Gut-Skin Axis}

Cross talk between the skin and other organ systems can be readily assumed on the basis of the number of cutaneous diseases that commonly co-manifest with non-cutaneous disorders [4]. A seminal case-control study published by Rainer et al. in 2015 reported a significant association between rosacea and a variety of systemic disorders including allergies, respiratory disease, GI disorders, hypertension, urogenital disease, and female hormonal imbalance [16]. In a later population-based cohort study of 50,000 Danish patients with rosacea by Egeberg et al., the prevalence of celiac disease (CeD), Crohn's disease (CD), ulcerative colitis (UC), small intestinal bacterial overgrowth (SIBO), and irritable bowel syndrome (IBS) were all 
significantly higher among patients with rosacea as compared with controls [17]. These studies, and many others, substantiate the notion of a gut-skin axis. In fact, Nam et al. go a step further, describing the "gut-brain-skin axis" based on clinical evidence demonstrating amelioration of cutaneous inflammation following the administration of prebiotics and probiotics and the exhibition of similar neuronal and inflammatory activity in both the gut and skin $[13,18]$.

\section{Helicobacter pylori's Role}

H. pylori, a helical gram-negative bacteria that resides in the stomach, is one of the most common human pathogens, likely infecting more than $50 \%$ of the general population $[4,19]$. It has been recognized as a causative factor of chronic gastritis, peptic ulcers, and gastric cancers [4]. Seropositivity is also linked with cardiovascular, respiratory, neurologic, and autoimmune disease as well as rosacea, psoriasis, and idiopathic urticaria in the skin [4].

$H$. pylori's role in rosacea's pathogenesis is unclear but has long been suspected because of the high prevalence of seropositivity in the rosacea population [7]. In a paper by Utas et al. in 1999, it was originally reported that $H$. pylori eradication therapy improved rosacea symptoms [20], and subsequent studies have corroborated these findings. However, since then, conflicting evidence has also arisen [4]. Two comparative studies by Bamford et al. and Herr et al. found no significant difference in rosacea symptoms between treated and untreated patients with H. pylori [21, 22]. The pathogenic link is difficult to establish, as antibiotics are independently helpful in the treatment of each disease [2].

Various mechanisms of this theorized association have been proposed, one of which describes $H$. pylori as a trigger of inflammation via cytotoxins and gastrin-induced flushing [4]. It has also been speculated that systemic effects are due to increased mucosal permeability to alimentary antigens, an autoimmune mechanism via the production of cross-reactive antibodies, or the impairment of vascular integrity [19]. Interestingly, increased mucosal permeability of the stomach and intestine has been appreciated with $H$. pylori infection [19].
Alterations in the Gastrointestinal Microbiome In a healthy state, a diverse enteric microbiome prevents the passage of noxious substances across the gut mucosal surface [13]. A compromise in the mucosa, either through changes in the microbiome or autoimmune disease, may result in pernicious substances entering the bloodstream and affecting peripheral sites [13]. Previous studies have linked inflammatory skin diseases with an imbalanced gut microbiome $[2,23,24]$. Resident gut bacteria may serve as the underlying trigger to an exaggerated immune response, and the improvements in both IBD and rosacea symptoms with oral metronidazole therapy support this notion [25]. Another theory posits that dysbiosis of intestinal bacteria results in activation of the plasma kallikrein-kinin system (PKKS) pathways, leading to downstream neurogenic inflammation [9]. Kendall points out that the PKKS is significantly activated in patients with intestinal inflammation and is likewise consistently elevated in patients with rosacea versus controls [9]. Furthermore, increases in plasma bradykinin concentrations correlate closely with rosacea flushing episodes induced by alcohol consumption $[9,25]$.

Nam et al. aimed to investigate the link between rosacea and the enteral microbiome [18]. Gene and metagenome sequence analysis via 16S rRNA PCR was conducted amongst 12 Korean women with rosacea [18]. The authors observed a link between intestinal microbial alterations and rosacea, whereby patients had different compositions but similar abundance of enteral microbiota compared with rosaceafree controls [18].

\section{IBD}

An association between rosacea and IBD, as both diseases are conceived as inflammatory, occurs at the surface of skin or mucosa, and involves an aberrant innate immune reaction in genetically susceptible hosts [26, 27]. It well established that IBD is associated with cutaneous manifestations such as erythema nodosum, pyoderma gangrenosum, and psoriasis [26]. Recent studies investigate an additional link between IBD and rosacea. 
One such study was conducted in the UK by Spoendlin et al. which demonstrated an increased risk of rosacea in patients with UC and CD compared to patients without IBD [26]. In fact, the risk was almost threefold during the period directly following UC diagnosis, a time of presumably high inflammatory activity [26]. Further, the degree of IBD severity was positively associated with rosacea severity [26]. An observational cohort study among US women reported a significant association between rosacea and subsequent development of CD after adjustment for measured cofounders, including smoking [28]. Similarly, studies from Taiwan, Korea, and Denmark further substantiate a rosacea-IBD association [11, 17, 29], and recent genetic studies have shown that a certain MHC Class II protein-encoding gene (HLA$\left.D R B 1{ }^{*} 03: 01\right)$ that plays an important role in IBD pathogenesis is also associated with rosacea [30-32].

Although speculative, it is possible that shared autoimmune susceptibility may provide a link between rosacea and GI disorders [17]. It is known that extraintestinal manifestations of CD involve immune alterations, and this could also be at play in rosacea pathophysiology [6]. Further, there may be a link between the previously discussed gut microbiome, IBD, and rosacea pathogenesis. A retrospective chart review by Weinstock investigated the effects of rifaximin and adalimumab, common CD therapies, in patients with concomitant $\mathrm{CD}$ and rosacea [6]. Of the four patients studied, two had complete remission of rosacea and GI symptoms with rifaximin alone, and two experienced complete remission once adalimumab was added [6]. This study hints at the involvement of GI bacteria in both CD and rosacea pathophysiology [6]. Further, improvement of rosacea with the addition of adalimumab implicates $\mathrm{TNF} \alpha$ as a player in the dual development of rosacea and CD [6].

In addition to IBD, new data has linked rosacea with IBS and CeD [25]. The Danish cohort study by Egeberg et al. noted increased risk of new-onset IBS and subsequently diagnosed CeD in subjects with rosacea [17], and a recent genome-wide association study (GWAS) identified shared genetic risk loci for rosacea and celiac disease [31].

\section{SIBO}

Numerous studies highlight the potential pathogenic role of SIBO in the development of rosacea [33]. According to a study by Parodi et al., patients with rosacea were 13 times more likely to have SIBO than control patients [33]. Further, eradication of SIBO with rifaximin led to a significant regression of skin lesions in almost all patients, which persisted in the majority of patients through 3-year follow-up [33]. Contrastingly, the majority of SIBO-negative patients did not obtain any improvement after antibiotic therapy [33]. In a study by Weinstock, a total of 32/63 patients seen in GI clinic with rosacea were given the diagnosis of SIBO compared with $7 / 30$ control subjects from the general population [6]. Of the patients with SIBO, 28 were treated with rifaximin, and $46 \%$ reported cleared or markedly improved rosacea, $25 \%$ reported moderately improved rosacea, and $11 \%$ reported mildly improved rosacea [6]. All four patients with ocular rosacea and SIBO reported marked improvement [6].

Investigators theorize that circulating cytokines, particularly $\mathrm{TNF} \alpha$, may play a role in this striking relationship [33]. In addition to $\mathrm{TNF} \alpha$, SIBO may alter immunity and trigger rosacea by the augmentation of other cytokines which suppress IL-17 and stimulate the Th1mediated immune response $[6,13]$.

\section{Therapeutic Strategies}

\section{Triggers}

Although a number of rosacea treatments currently exist, most target distinct symptoms rather than the underlying cause of disease. Management usually starts with extensive patient education regarding trigger avoidance, and such triggers can include sun exposure, temperature changes, spicy foods, and alcohol consumption $[5,17,34]$. Maintaining a diary is also a useful means of identifying stimuli that exacerbate symptoms [34]. Additional emphasis should be placed on avoidance of irritant cosmetic products, and the use of daily sunscreen is 
recommended given the well-known aggravating effects of UV light [34]. However, because trigger avoidance does not invariably lead to symptom remission, pharmacologic management is often used in conjunction to counseling.

\section{Pharmacologic Management}

In general, an algorithmic approach based on increasing symptom severity and subtype of rosacea is followed (Table 1). Erythema of the face can first be managed directly with topical $\beta$ blockers or $\alpha 2$-adrenergic agonists such as brimonidine tartrate $[5,34,35]$. Oral $\beta$-blockers, too, have been successfully employed for this purpose [35]. Topical antibiotics and antiparasitics are common pharmacologic tools employed in rosacea management, and these agents include azelaic acid, metronidazole, and ivermectin $[5,34,36]$. It has been suggested that metronidazole has acaricidal effects which may complement the anti-Demodex activity of antiparasitics such as ivermectin [36]. In a study by Margalit et al., a comparison of individuals treated with a combination of metronidazole and ivermectin rather than ivermectin alone showed a greater reduction in the Demodex population [36]. Other topical treatments less frequently prescribed include a combination of $10 \%$ sodium sulfacetamide and $5 \%$ sulfur, permethrin cream, and retinoids; however, there is limited data to support these treatments [34].

For patients with symptoms refractory to topical therapy, tetracycline compounds have been the mainstay of treatment [2, 37]. It remains unclear whether their effectiveness is due to their antimicrobial properties or their ability to inhibit protease and matrix metalloproteinase activity, thus reducing inflammation [36]. This conundrum is showcased by the US Food and Drug Administration (FDA)-approved treatment of rosacea with a sub-antimicrobial dose of doxycycline [36]. Finally, for severe cases that are either refractory to oral antibiotics or recur after antibiotic discontinuation, oral treatment with low-dose isotretinoin for 12 to 16 weeks has been shown to be effective [34].

Therapeutic strategies that directly modify the gut microbiome have also been shown to be effective for rosacea. In 2016, Manzhalii et al. sought to evaluate the effect of oral Escherichia coli Nissle application on the outcome of intestinal-borne dermatoses including PPR, acne, and seborrheic dermatitis [38]. Their primary goal was a shift of the microbiome towards less aggressive bacterial colonization, thereby assuaging the overstimulation of the immune system [38]. By means of special adhesive organelles, this strain of $E$. coli has the ability to form a biofilm by attaching to the large intestine's mucous membrane and arranging in microcolonies [38]. An added colonizing benefit is proffered by the presence of flagella, conferring significant mobility [38]. Regarding the desired shift towards more benign colonization, E. coli inhibits the growth of gram-negative anaerobic bacteria by its secretion of antimicrobial substances and siderophores, which prevent the growth of certain pathological bacteria strains through the entrapment of iron [38]. Of those patients treated with Nissle application, 89\% responded with significant mitigation or complete recovery in contrast to $56 \%$ improvement in the control arm [38].

Fortuna et al. treated a patient with PPR, blepharitis, and conjunctivitis with an 8-week course of doxycycline along with probiotic therapy twice daily [39]. The patient returned with significant improvement of both cutaneous and ocular manifestations after this therapeutic course. Doxycycline was discontinued but the sustained use of probiotics was suggested. The patient was without relapse after 6 months of follow-up [39].

\section{Role of Laser Therapy}

Vascular laser therapy for rosacea began in the early 1980s with the argon laser [40]. Although light-based therapies are widely used in the treatment of erythema and telangiectasia, treatment modalities have been primarily investigated in observational studies, and randomized control trials with adequate population sizes are lacking [34]. In addition to mitigating telangiectasias, the focus for rosacea laser and light therapies has come to encompass a broader approach, including the reorganization and remodeling of dystrophic dermal connective tissue and strengthening of the 
Table 1 Rosacea therapy: topical and systemic treatments

\begin{tabular}{|c|c|c|}
\hline Drug & Mechanism of action & Side effects \\
\hline \multicolumn{3}{|l|}{ Topical } \\
\hline $\begin{array}{l}\text { Brimonidine tartrate }(0.33 \% \\
\text { gel) }\end{array}$ & Vasoconstrictive $\alpha_{2}$-adrenergic agonist & $\begin{array}{l}\text { Erythema, flushing, skin burning, } \\
\text { contact dermatitis }\end{array}$ \\
\hline $\begin{array}{l}\text { Azelaic acid }(20 \% \text { cream/lotion } \\
\text { or } 15 \% \text { foam/gel) twice daily }\end{array}$ & $\begin{array}{l}\text { May be related to reductions in mRNA for } \\
\text { cathelicidin and kallikrein-5 }\end{array}$ & Burning, itching, stinging \\
\hline $\begin{array}{l}\text { Metronidazole }(0.75 \% \text { cream/ } \\
\text { gel/lotion; } 1 \% \text { cream/gel }) \text { once } \\
\text { or twice daily }\end{array}$ & $\begin{array}{l}\text { May involve antimicrobial, anti-inflammatory, } \\
\text { and/or antioxidant properties }\end{array}$ & Irritation, xeroderma, stinging \\
\hline $\begin{array}{l}\text { Oxymetazoline } \mathrm{HCl}(1 \% \\
\text { cream })\end{array}$ & $\alpha_{1 \mathrm{~A}^{-} \text {-adrenergic agonist }}$ & $\begin{array}{l}\text { Contact dermatitis, worsening of } \\
\text { inflammatory rosacea lesions, } \\
\text { pain, pruritis, erythema }\end{array}$ \\
\hline $\begin{array}{l}\text { Ivermectin ( } 1 \% \text { cream) once } \\
\text { daily }\end{array}$ & $\begin{array}{l}\text { May be related to anti-Demodex and anti- } \\
\text { inflammatory activity }\end{array}$ & NA \\
\hline $\begin{array}{l}\text { Sodium sulfacetamide (10\%) } \\
\text { and sulfur }(5 \%) \text { cream or } \\
\text { lotion once or twice daily }\end{array}$ & $\begin{array}{l}\text { Antiseptic, antiparasitic, antiseborrheic, and } \\
\text { keratolytic }\end{array}$ & Local irritation, allergic reactions \\
\hline $\begin{array}{l}\text { Erythromycin ( } 2 \% \text { solution }) \\
\text { twice daily }\end{array}$ & Antimicrobial and anti-inflammatory properties & $\begin{array}{l}\text { Erythema, pruritus, burning, } \\
\text { stinging }\end{array}$ \\
\hline Clindamycin ( $1 \%$ lotion) daily & Antimicrobial and anti-inflammatory properties & $\begin{array}{l}\text { Xeroderma, erythema, burning, } \\
\text { pruritus }\end{array}$ \\
\hline $\begin{array}{l}\text { Benzoyl peroxide } 5 \% \text { plus } \\
\text { clindamycin } 1 \% \text { daily }\end{array}$ & $\begin{array}{l}\text { Free radical oxidation of anaerobic bacteria and } \\
\text { antimicrobial activity }\end{array}$ & Xeroderma, itching, stinging \\
\hline $\begin{array}{l}\text { Permethrin ( } 5 \% \text { cream) } \\
\text { daily-weekly }\end{array}$ & $\begin{array}{l}\text { Unknown, may be related to anti-Demodex } \\
\text { activity }\end{array}$ & Burning, numbness, tingling \\
\hline $\begin{array}{l}\text { Tretinoin }(0.025 \% \text { cream; } \\
0.05 \% \text { cream; } 0.01 \% \text { gel }) \text { daily }\end{array}$ & Alters epidermal keratinization & Irritation \\
\hline Timolol & $\beta_{1}$-adrenergic and $\beta_{2}$-adrenergic antagonist & $\begin{array}{l}\text { Xeroderma, burning, stinging, } \\
\text { erythema }\end{array}$ \\
\hline \multicolumn{3}{|l|}{ Systemic } \\
\hline $\begin{array}{l}\text { Doxycycline } 40-100 \mathrm{mg} \\
\text { daily-twice daily, } 4-8 \text { weeks }\end{array}$ & $\begin{array}{l}\text { Possible antimicrobial and anti-inflammatory } \\
\text { properties }\end{array}$ & $\begin{array}{l}\text { Gastrointestinal distress, } \\
\text { photosensitivity }\end{array}$ \\
\hline $\begin{array}{l}\text { Minocycline } 50-100 \mathrm{mg} \text { twice } \\
\text { daily for } 4-8 \text { weeks }\end{array}$ & $\begin{array}{l}\text { Possible antimicrobial and anti-inflammatory } \\
\text { properties }\end{array}$ & $\begin{array}{l}\text { Gastrointestinal distress, } \\
\text { photosensitivity, vertigo, lupus- } \\
\text { like syndrome, skin discoloration }\end{array}$ \\
\hline $\begin{array}{l}\text { Tetracycline } 250-500 \mathrm{mg} \text { twice } \\
\text { daily for } 4-8 \text { weeks }\end{array}$ & $\begin{array}{l}\text { Possible antimicrobial and anti-inflammatory } \\
\text { properties; reduction of matrix } \\
\text { metalloproteinase activity }\end{array}$ & $\begin{array}{l}\text { Gastrointestinal distress, } \\
\text { photosensitivity }\end{array}$ \\
\hline
\end{tabular}


Table 1 continued

\begin{tabular}{|c|c|c|}
\hline Drug & Mechanism of action & Side effects \\
\hline $\begin{array}{l}\text { Erythromycin } 250-500 \mathrm{mg} \\
\text { once-twice daily for } 4-8 \text { weeks }\end{array}$ & $\begin{array}{l}\text { Possible antimicrobial and anti-inflammatory } \\
\text { properties }\end{array}$ & $\begin{array}{l}\text { Gastrointestinal distress, headache, } \\
\text { pruritus }\end{array}$ \\
\hline $\begin{array}{l}\text { Azithromycin } 250-500 \mathrm{mg} \\
\text { thrice weekly for } 4-8 \text { weeks }\end{array}$ & $\begin{array}{l}\text { Possible antimicrobial and anti-inflammatory } \\
\text { properties }\end{array}$ & $\begin{array}{l}\text { Gastrointestinal distress, } \\
\text { hepatotoxicity, QT prolongation }\end{array}$ \\
\hline $\begin{array}{l}\text { Metronidazole } 200 \mathrm{mg} \text { once or } \\
\text { twice daily for } 4-8 \text { weeks }\end{array}$ & $\begin{array}{l}\text { Possible antimicrobial and anti-inflammatory } \\
\text { properties }\end{array}$ & $\begin{array}{l}\text { Gastrointestinal distress, disulfiram- } \\
\text { like reaction }\end{array}$ \\
\hline Isotretinoin $0.3 \mathrm{mg} / \mathrm{kg} /$ day & Alters epidermal keratinization & $\begin{array}{l}\text { Teratogenic, facial dermatitis, } \\
\text { cheilitis, dry skin, abdominal pain }\end{array}$ \\
\hline Erenumab & $\begin{array}{l}\text { Calcitonin gene-related peptide receptor } \\
\text { antagonist }\end{array}$ & Constipation, muscle cramps \\
\hline Rifaximin & Antimicrobial & Dizziness, fatigue, nausea \\
\hline \multicolumn{3}{|l|}{ Other } \\
\hline $\begin{array}{l}\text { Pulsed dye laser therapy, intense } \\
\text { pulsed light, and photodynamic } \\
\text { therapy }\end{array}$ & $\begin{array}{l}\text { Light energy is absorbed by hemoglobin in } \\
\text { cutaneous vessels, causing vessel heating and } \\
\text { coagulation }\end{array}$ & $\begin{array}{l}\text { Skin dyspigmentation, blistering, } \\
\text { ulceration, and scarring }\end{array}$ \\
\hline Probiotics & $\begin{array}{l}\text { Suppression of pathogenic intestinal bacteria, } \\
\text { improvement of intestinal barrier function, } \\
\text { modulation of immune system via production } \\
\text { of protective cytokines }\end{array}$ & Gas, bloating, diarrhea \\
\hline Prebiotics & $\begin{array}{l}\text { Carbohydrates that serve as a major substrate for } \\
\text { the growth of beneficial gut microbiota }\end{array}$ & Gas, bloating, diarrhea \\
\hline
\end{tabular}

epidermal barrier [40]. Unfortunately, this treatment method is limited by cost, as the majority of applications are not covered by medical insurance [40].

\section{Future Therapies}

Current studies are underway which investigate the role of erenumab, a human monoclonal antibody that antagonizes the calcitonin generelated peptide receptor (CGRPR), timolol, a nonselective $\beta$-adrenergic antagonist, and rifaximin, a semisynthetic nonsystemic antibiotic that acts as an intraluminal agent [41-43].

The role of pulsed dye laser treatment with oxymetazoline hydrochloride $1 \%$ cream for the treatment of the ETR subtype is also being studied [44]. The results of these studies will be formative in the future rosacea treatment arsenal.

\section{CONCLUSION}

The exact pathophysiology of rosacea is still poorly understood, but current theories focus on the role of the cutaneous microbiome, specifically $D$. folliculorum and a few commensal bacteria, in the propagation of an inflammatory response. However, the theory of microbial induction extends beyond the skin to include the GI microbiome and complications therein. Additional GI pathologies have been 
implicated, including infection by $H$. pylori and IBD. Treatment of rosacea with topical antibiotics and antiparasitics has long reigned supreme, followed by oral agents from the tetracycline class. Future studies should further investigate the role of the GI microbiome in the pathogenesis of rosacea, as intraluminal agents such as rifaximin have already been shown to have beneficial effects.

\section{ACKNOWLEDGEMENTS}

Funding. No funding or sponsorship was received for this study or publication of this article.

Authorship. All named authors meet the International Committee of Medical Journal Editors (ICMJE) criteria for authorship for this article, take responsibility for the integrity of the work as a whole, and have given their approval for this version to be published.

Disclosures. Hala Daou, Michela Paradiso, Dr. Kerry Hennessy and Dr. Lucia SeminarioVidal have nothing to disclose.

Compliance with Ethics Guidelines. This article is based on previously conducted studies and does not contain any studies with human participants or animals performed by any of the authors.

Data Availability. Data sharing is not applicable to this article as no datasets were generated or analyzed during the current study.

Open Access. This article is licensed under a Creative Commons Attribution-NonCommercial 4.0 International License, which permits any non-commercial use, sharing, adaptation, distribution and reproduction in any medium or format, as long as you give appropriate credit to the original author(s) and the source, provide a link to the Creative Commons licence, and indicate if changes were made. The images or other third party material in this article are included in the article's Creative Commons licence, unless indicated otherwise in a credit line to the material. If material is not included in the article's Creative Commons licence and your intended use is not permitted by statutory regulation or exceeds the permitted use, you will need to obtain permission directly from the copyright holder. To view a copy of this licence, visit http://creativecommons.org/licenses/by$\mathrm{nc} / 4.0 /$.

\section{REFERENCES}

1. Holmes AD, Spoendlin J, Chien AL, Baldwin $\mathrm{H}$, Chang ALS. Evidence-based update on rosacea comorbidities and their common physiologic pathways. J Am Acad Dermatol. 2018;78(1):156-66.

2. Weiss E, Katta R. Diet and rosacea: the role of dietary change in the management of rosacea. Dermatol Pract Concept. 2017;7(4):31-7.

3. Wong F, Rayner-Hartley E, Byrne MF. Extraintestinal manifestations of Helicobacter pylori: a concise review. World J Gastroenterol. 2014;20(34): 11950-61.

4. Holmes AD. Potential role of microorganisms in the pathogenesis of rosacea. J Am Acad Dermatol. 2013;69(6):1025-32.

5. Rastogi V, Singh D, Mazza JJ, Parajuli D, Yale SH. Flushing disorders associated with gastrointestinal symptoms: part 1, neuroendocrine tumors, mast cell disorders and hyperbasophila. Clin Med Res. 2018;16(1-2):16-28.

6. Weinstock L. Crohn's disease and rosacea: effect of rifaximin and adalimumab. Am J Gastroenterol. 2011;106:S449.

7. Two AM, Wu W, Gallo RL, Hata TR. Rosacea: part I. Introduction, categorization, histology, pathogenesis, and risk factors. J Am Acad Dermatol. 2015;72(5):749-58 (quiz 759-760).

8. O'Reilly N, Menezes N, Kavanagh K. Positive correlation between serum immunoreactivity to Demodex-associated Bacillus proteins and erythematotelangiectatic rosacea. $\mathrm{Br} \mathrm{J}$ Dermatol. 2012;167(5):1032-6.

9. Kendall SN. Remission of rosacea induced by reduction of gut transit time. Clin Exp Dermatol. 2004;29(3):297-9. 
10. Wang R, Farhat M, Na J, Li R, Wu Y. Bacterial and fungal microbiome characterization in patients with rosacea and healthy controls. Br J Dermatol. 2020. https://doi.org/10.1111/bjd.19315.

11. Kim M, Choi KH, Hwang SW, Lee YB, Park HJ, Bae JM. Inflammatory bowel disease is associated with an increased risk of inflammatory skin diseases: a population-based cross-sectional study. J Am Acad Dermatol. 2017;76(1):40-8.

12. Casas C, Paul C, Lahfa M, et al. Quantification of Demodex folliculorum by PCR in rosacea and its relationship to skin innate immune activation. Exp Dermatol. 2012;21(12):906-10.

13. Searle T, Ali FR, Carolides S, Al-Niaimi F. Rosacea and the gastrointestinal system. Australas J Dermatol. 2020. https://doi.org/10.1111/ajd.13401.

14. O'Reilly N, Bergin D, Reeves EP, McElvaney NG, Kavanagh K. Demodex-associated bacterial proteins induce neutrophil activation. $\mathrm{Br} \mathrm{J}$ Dermatol. 2012;166(4):753-60.

15. Whitfeld M, Gunasingam N, Leow LJ, Shirato K, Preda V. Staphylococcus epidermidis: a possible role in the pustules of rosacea. J Am Acad Dermatol. 2011;64(1):49-52.

16. Rainer BM, Fischer AH, Luz Felipe da Silva D, Kang $\mathrm{S}$, Chien AL. Rosacea is associated with chronic systemic diseases in a skin severity-dependent manner: results of a case-control study. J Am Acad Dermatol. 2015;73(4):604-8.

17. Egeberg A, Weinstock LB, Thyssen EP, Gislason GH, Thyssen JP. Rosacea and gastrointestinal disorders: a population-based cohort study. Br J Dermatol. 2017;176(1):100-6.

18. Nam JH, Yun Y, Kim HS, et al. Rosacea and its association with enteral microbiota in Korean females. Exp Dermatol. 2018;27(1):37-42.

19. Wedi B, Kapp A. Helicobacter pylori infection in skin diseases: a critical appraisal. Am J Clin Dermatol. 2002;3(4):273-82.

20. Utas S, Ozbakir O, Turasan A, Utas C. Helicobacter pylori eradication treatment reduces the severity of rosacea. J Am Acad Dermatol. 1999;40(3):433-5.

21. Bamford JT, Tilden RL, Blankush JL, Gangeness DE. Effect of treatment of Helicobacter pylori infection on rosacea. Arch Dermatol. 1999;135(6):659-63.

22. Herr H, You CH. Relationship between Helicobacter pylori and rosacea: it may be a myth. J Korean Med Sci. 2000;15(5):551-4.
23. Chen WX, Ren LH, Shi RH. Enteric microbiota leads to new therapeutic strategies for ulcerative colitis. World J Gastroenterol. 2014;20(42):15657-63.

24. Szántó M, Dózsa A, Antal D, Szabó K, Kemény L, Bai P. Targeting the gut-skin axis-probiotics as new tools for skin disorder management? Exp Dermatol. 2019;28(11):1210-8.

25. Vera N, Patel NU, Seminario-Vidal L. Rosacea comorbidities. Dermatol Clin. 2018;36(2):115-22.

26. Spoendlin J, Karatas G, Furlano RI, Jick SS, Meier CR. Rosacea in patients with ulcerative colitis and Crohn's disease: a population-based case-control study. Inflamm Bowel Dis. 2016;22(3):680-7.

27. Haber R, El Gemayel M. Comorbidities in rosacea: a systematic review and update. J Am Acad Dermatol. 2018;78(4):786-792.e788.

28. Li WQ, Cho E, Khalili H, Wu S, Chan AT, Qureshi AA. Rosacea, use of tetracycline, and risk of incident inflammatory bowel disease in women. Clin Gastroenterol Hepatol. 2016;14(2):220-225.e221-3.

29. Wu CY, Chang YT, Juan CK, et al. Risk of inflammatory bowel disease in patients with rosacea: results from a nationwide cohort study in Taiwan. J Am Acad Dermatol. 2017;76(5):911-7.

30. Goyette P, Boucher G, Mallon D, et al. High-density mapping of the MHC identifies a shared role for HLA-DRB1*01:03 in inflammatory bowel diseases and heterozygous advantage in ulcerative colitis. Nat Genet. 2015;47(2):172-9.

31. Chang ALS, Raber I, Xu J, et al. Assessment of the genetic basis of rosacea by genome-wide association study. J Invest Dermatol. 2015;135(6):1548-55.

32. Reinholz M, Ruzicka T, Schauber J. Cathelicidin LL37: an antimicrobial peptide with a role in inflammatory skin disease. Ann Dermatol. 2012;24(2): 126-35.

33. Parodi A, Paolino S, Greco A, et al. Small intestinal bacterial overgrowth in rosacea: clinical effectiveness of its eradication. Clin Gastroenterol Hepatol. 2008;6(7):759-64.

34. van Zuuren EJ. Rosacea. $\mathrm{N}$ Engl J Med. 2017;377(18):1754-64.

35. Logger JGM, Olydam JI, Driessen RJB. Use of betablockers for rosacea-associated facial erythema and flushing: a systematic review and update on proposed mode of action. J Am Acad Dermatol. 2020;83(4):1088-97.

36. Margalit A, Kowalczyk MJ, Żaba R, Kavanagh K. The role of altered cutaneous immune responses in the 
induction and persistence of rosacea. J Dermatol Sci. 2016;82(1):3-8.

37. Park JM, Mun JH, Song M, et al. Propranolol, doxycycline and combination therapy for the treatment of rosacea. J Dermatol. 2015;42(1):64-9.

38. Manzhalii E, Hornuss D, Stremmel W. Intestinalborne dermatoses significantly improved by oral application of Escherichia coli Nissle 1917. World J Gastroenterol. 2016;22(23):5415-21.

39. Fortuna MC, Garelli V, Pranteda G, et al. A case of scalp rosacea treated with low dose doxycycline and probiotic therapy and literature review on therapeutic options. Dermatol Ther. 2016;29(4):249-51.

40. Pelle MT, Crawford GH, James WD. Rosacea: II. Therapy. J Am Acad Dermatol. 2004;51(4):499-12 (quiz 513-494).
41. Efficacy and tolerability of erenumab in the management of persistent redness and flushing in rosacea. https://ClinicalTrials.gov/show/NCT04419 259. Accessed 12 Sept 2020.

42. Timolol for the treatment of acne and rosacea. https://ClinicalTrials.gov/show/NCT02774590. Accessed 12 Sept 2020.

43. Safety and efficacy of rifaximin in patients with papulopustular rosacea and positive lactulose breath test. https://ClinicalTrials.gov/show/ NCT03864978. Accessed 12 Sept 2020.

44. Pulsed dye laser treatment and oxymetazoline hydrochloride $(\mathrm{HCl}) 1 \%$ cream for erythematotelangiectatic rosacea. https://ClinicalTrials.gov/ show/NCT04153188. Accessed 12 Sept 2020. 